\section{Kidney \\ Blood Pressure Research}

\title{
Maternal Vitamin D Deficiency and Fetal Programming - Lessons Learned from Humans and Mice
}

\author{
Christoph Reichetzeder ${ }^{\mathrm{a}} \quad$ Hong Chen $^{\mathrm{b}} \quad$ Michael Föller $^{\mathrm{b}} \quad$ Torsten Slowinskic $^{\mathrm{c}}$ \\ Jian Lid ${ }^{d}$ You-Peng Chen ${ }^{\mathrm{e}}$ Florian Lang ${ }^{\mathrm{b}}$ Berthold Hochera \\ aInstitute of Nutritional Science, University of Potsdam, Potsdam-Rehbrücke; bepartment of \\ Physiology, University of Tübingen; 'Department of Nephrology, Campus Mitte, Charité, Berlin, \\ Germany; ${ }^{\mathrm{d} D e p a r t m e n t}$ of Clinical Medicine, Medical college of Hunan Normal University, Changsha; \\ eDepartment of Infectious Diseases, the First Affiliated Hospital of Jinan University of Guangzhou, China
}

\section{Key Words}

Vitamin D - Birth weight - Preterm delivery - Fetal programming - Glucose tolerance • Cardiovascular diseases

\begin{abstract}
Background/Aims: Cardiovascular disease partially originates from poor environmental and nutritional conditions in early life. Lack of micronutrients like 25 hydroxy vitamin $\mathrm{D}_{3}$ (25OHD) during pregnancy may be an important treatable causal factor. The present study explored the effect of maternal 25OHD deficiency on the offspring. Methods: We performed a prospective observational study analyzing the association of maternal $250 \mathrm{HD}$ deficiency during pregnancy with birth outcomes considering confounding. To show that vitamin D deficiency may be causally involved in the observed associations, mice were set on either 25OHD sufficient or insufficient diets before and during pregnancy. Growth, glucose tolerance and mortality was analyzed in the F1 generation. Results: The clinical study showed that severe 25OHD deficiency was associated with low birth weight and low gestational age. ANCOVA models indicated that established confounding factors such as offspring sex, smoking during pregnancy and maternal BMI did not influence the impact of $25 \mathrm{OHD}$ on birth weight. However, there was a significant interaction between 25OHD and gestational age. Maternal 25OHD deficiency was also independently associated with low APGAR scores 5 minutes postpartum. The offspring of $25 \mathrm{OHD}$ deficient mice grew slower after birth, had an impaired glucose tolerance shortly after birth and an increased mortality during follow-up. Conclusions: Our study demonstrates an association between maternal $25 \mathrm{OHD}$ and offspring birth weight. The effect of 25OHD on
\end{abstract}

Christoph Reichetzeder and Hong Chen contributed equally to this work.

Prof. Dr. Berthold Hocher

University of Potsdam; Institute of Nutritional Science; Arthur-Scheunert-Allee 114-116; 14558 Nuthetal, Potsdam (Germany) Tel. +39 33200/88-5508, Fax +39 33200/88-5541,

E-Mail hocher@uni-potsdam.de, Homepage: http://www.uni-potsdam.de/eem 


\section{Kidney Blood Pressure Research}

Kidney Blood Press Res 2014;39:315-329

DOI: 10.1159/000355809
Published onIIne: September 19, 2014

(C) 2014 S. Karger AG, Basel

www.karger.com/kbr

Reichetzeder/Chen/Föller/Slowinski/Li/Chen/Lang/Hocher: Vitamin D and Pregnancy Outcome

birth weight seems to be mediated by vitamin $D$ controlling gestational age. Results from an animal experiment suggest that gestational $250 \mathrm{HD}$ insufficiency is causally linked to adverse pregnancy outcomes. Since birth weight and prematurity are associated with an adverse cardiovascular outcome in later life, this study emphasizes the need for novel monitoring and treatment guidelines of vitamin D deficiency during pregnancy.

Copyright (C) 2014 S. Karger AG, Basel

\section{Introduction}

Fetal programming, a theory of developmental origins of disease, refers to adaptive processes of the fetus to adverse environmental cues during gestation, which can have longterm effects on physiology, metabolism and therefore health status of an individual. Until now numerous epidemiological studies were able to show that effects of fetal programming can translate into a low birth weight, which is an independent risk factor for hypertension, cardiovascular and metabolic diseases in later life [1]. More and more evidence is accumulating that preterm birth is a similarly important risk factor for an elevated adulthood morbidity and mortality [2]. Thus, more information is needed on environmental cues triggering fetal programming.

Vitamin D, a secosteroid, is involved in the regulation of calcium and phosphate homeostasis and mediates a multitude of effects on various cell systems and signalling pathways beyond mineral metabolism. Currently it is estimated that vitamin D modulates about $10 \%$ of the whole human genome [3], underlining a putative major role in developmental processes [4-6]. Vitamin D plays an important role during human pregnancy. In early phases of pregnancy vitamin D triggers the decidualisation of the endometrium, a process relevant for the implantation of the blastocyst [7]. At the end of the first trimester various hormones are required for the maintenance of pregnancy. Invitro studies suggest that vitamin D supports the expression and secretion of human choriongonadotropin, human placental lactogen, estradiol and progesterone by placental cells [8].

Vitamin D hypovitaminosis, especially among pregnant women, is a major public health problem with a very high prevalence ranging from 18 to 84\%, depending on the country of residence and local clothing customs $[9,10] .25$ hydroxy vitamin $\mathrm{D}_{3}(250 \mathrm{HD})$ is considered the storage form of vitamin D and plasma concentrations of 250HD serve as a suitable indicator of the vitamin D status [8]. It is still unclear, whether the ideal level of 250HD should differ from documented optimal levels for non-pregnant adults or if vitamin D should be routinely supplemented during pregnancy. Being pregnant and deficient for 250HD could reduce maternal $250 \mathrm{HD}$ levels even further, although results from observational studies are not completely clear, either showing no change or a decline of maternal 250HD levels during pregnancy $[11,12]$.

250HD deficiency may be an independent risk factor for pregnancy and birth complications [13]. Maternal complications range from decreased weight gain [14], primary cesarean sections [15], bacterial vaginosis [16], osteomalacia [17] to gestational diabetes [14], hypertension and pre-eclampsia [13]. In the newborn, maternal 250HD deficiency has been linked to hypocalcemia, poor weight gain, impaired development and rickets [18]. Current literature suggests that there is association between 250HD hypovitaminosis and adverse pregnancy outcomes such as impaired fetal growth and preterm birth, however with conflicting results [19-24].

\section{Materials and Methods}

\section{Clinical study}

All research involving human participants has been approved by the authors' Institutional Review Board (IRB) of the university hospital Charité, Berlin, Germany, and all clinical investigations were 


\section{Kidney Blood Pressure Research}

Kidney Blood Press Res 2014;39:315-329

\begin{tabular}{l|l}
\hline DOI: 10.1159/000355809 & (c) 2014 S. Karger AG, Basel
\end{tabular}

Publisned ontıne: september 19, 2014

www.karger.com/kbr

Reichetzeder/Chen/Föller/Slowinski/Li/Chen/Lang/Hocher: Vitamin D and Pregnancy Outcome

conducted according to the principles expressed in the Declaration of Helsinki. Written informed consent was obtained from the participants. From 2007 to 2008 we invited a total of 547 mothers with singleton pregnancies delivering at Charité obstetrics department to participate in this prospective observational study. The study was approved by the local ethics committee. After obtaining written consent, structured interviews were performed with the mothers. Patients who fulfilled the criteria of a regular pregnancy were included regardless of the ethical background. However, the majority $(n=480)$ were of Caucasian ethnicity. The remaining patients were of African, Asian, or Arabic heritage. Data from the so called "Mutterpass", documenting the results of follow ups during pregnancy were also collected. The following data were added to our database: age, ethnicity, education, income, body height, weight before and during different time points of pregnancy, gravidity, parity, diabetes mellitus before or during pregnancy, incidence of hypertension before and during pregnancy, smoking status before and during pregnancy, systolic and diastolic blood pressure measurements recorded during pregnancy and the mode of delivery. Biometric data of the newborn were collected during the routine postnatal examination. Gestational age at delivery was based on last menstrual period, anamnestically assessed during the first pregnancy examination. For the final statistical analyses extreme cases with neonatal gestational ages $<28 \mathrm{weeks}$ and birth weights $<900 \mathrm{~g}$ were excluded. Following data of the newborn were added to the database: birth weight, birth length, head circumference, season of birth, child sex, Apgar score 5 minutes postnatally and Apgar score 10 minutes postnatally. Midwives collected maternal blood from a cubital vein in the delivery room or on the ward.

$250 H D$ is an established indicator of the vitamin D status [8], and current guidelines advise against the measurement of the active form of vitamin D, 1,25-Dihydroxyvitamin D3 [25], due to its short blood half life and technical difficulties to measure it.

For the analysis of 250HD heparinized collecting tubes were used and centrifuged at 2750g for 10 minutes at room temperature. Maternal plasma was then stored at $-80^{\circ} \mathrm{C}$ for further analysis.

250HD was measured in maternal plasma by Immundiagnostik AG (Bensheim) deploying a monoclonal antibody based quantitative ELISA assay. The measurable range was $1 \mathrm{nmol} / \mathrm{L}-240 \mathrm{nmol} / \mathrm{L}$. External controls were used for internal quality assurance. As 37 mothers displayed 250HD concentrations below the limit of detection, these values were adjusted to the limit of detection $(1 \mathrm{nmol} / \mathrm{L})$ times 0.5 , as recommended by the literature [26].

\section{Animal experiment}

All animal work has been conducted in accordance with national and international guidelines for the use of living animals and was approved by the Institutional Animal Care and Use Committee of the University of Tübingen, Germany and the state authorities of Baden-Württemberg. Male and female C57BL/6 mice were obtained from Charles River (Sulzfeld, Germany). The animals were kept at a temperature of $21 \pm 1^{\circ} \mathrm{C}$, were subjected to a 12-hour light/dark cycle and received chow and water ad libitum. At 3 weeks, female mice were subjected either to a diet containing 10,000 I.U./kg vitamin D3 (Altromin, Lage, Germany) or to a diet containing $<50$ I.U./kg vitamin D3 (Altromin, Lage, Germany). Mice were mated 4-5 weeks later with males kept on a standard diet (Ssniff, Soest, Germany). The F1 generation consisted of 63 animals from $250 \mathrm{HD}$ sufficient mothers and 57 animals from 250HD insufficient mothers. The respective diet was continued for the female mice until the offspring was weaned. After weaning, all mice received standard diet (Ssniff, Soest, Germany). Weight was monitored weekly starting on the day of birth. At an age of 55-60 days, an intraperitoneal glucose tolerance test was performed. To this end, mice were fasted overnight. After i.p. injection of $20 \%$ glucose-containing saline solution ( $2 \mathrm{mg} / \mathrm{g}$ b.w. glucose), glucose levels were determined in tail vein blood with a glucometer (Roche, Mannheim, Germany) at the indicated time points. At an age of 55 days blood pressure was measured in offspring of 250HD sufficient and insufficient mothers by tail cuff method (IITC Life Science, Woodlands Hills, CA, USA). The maternal 250HD status was also assessed in 3 animals of each diet group, using a competitive protein binding assay (K2110; Immundiagnostik AG, Bensheim; Germany) for the measurement of 250HD. Blood for 250HD analysis was taken at the age of $105 \pm 2$ days when the mice had been subjected to the respective diet for $83 \pm 2$ days.

\section{Statistical evaluation}

Data were analyzed using SPSS version 20.0 (SPSS, Inc, Chicago, IL, USA). Unpaired t-test was used when comparing two groups. Bivariate correlation analysis was assessed to detect possible confounders relevant to be included into statistical models. Additional established confounding factors of birth 


\section{Kidney Blood Pressure Research}

weight [27-29], such as offspring sex, smoking during pregnancy and maternal height and weight were included into the models. ANCOVA analysis was then used to confirm relevant confounding variables that independently influence birth weight or gestational age and to adjust for these in different statistical models. Graphs regarding differences in birth weight were calculated and compiled with Graphpad Prism 5 (GraphPad Software Inc., La Jolla, California, USA). Data and graphs from the animal experiment were also calculated and compiled with Graphpad Prism 5. Data regarding weight gain and glucose tolerance in the animal experiment were calculated using two-way ANOVA with a Bonferroni posttest. Survival was assessed by employing a Kaplan-Meier curve comparison. Probability values $<0.05$ were considered significant. The authors had full access to the data and take full responsibility for its integrity.

\section{Results}

\section{Clinical study}

Descriptive Data. Detailed descriptive statistics of the mothers and their newborns are displayed in Table 1.

Table 2 shows detailed descriptive statistics of the study population grouped according to the severity of 250HD deficiency. Cut-off values were chosen as follows: below the level of detection ( $<1 \mathrm{nmol} / \mathrm{L} ; \mathrm{n}=37$ ), severe deficiency ( $\geq 1$ to $<25 \mathrm{nmol} / \mathrm{L} ; \mathrm{n}=361$ ), moderate deficiency to sufficiency ( $\geq 25 \mathrm{nmol} / \mathrm{L} ; \mathrm{n}=149$ ). Significant group differences were calculated using ANOVA or Pearson's chi-squared test.

In the studied cohort we observed strong differences in maternal 250HD plasma concentrations, when grouping according to the level of education (Figure 1A; low education:

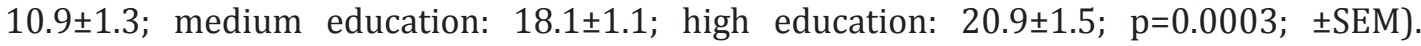
Additionally sorting maternal height according to the severity of 250HD deficiency revealed highly significant differences in maternal height (Figure 1B; <1 nmol/L: $163.9 \pm 1.2 \mathrm{~cm}$; $\geq 1$ to $<25 \mathrm{nmol} / \mathrm{L}$ : $166.3 \pm 0.4 \mathrm{~cm}$; $\geq 25 \mathrm{nmol} / \mathrm{L}: 168.9 \pm 0.5 \mathrm{~cm} ; \mathrm{p}<0.001 ; \pm S E M$ ). We also observed significant differences of $250 \mathrm{HD}$ plasma concentrations, when data were analyzed according to ethnicity (Caucasian; other; $19.3 \pm 0.9 \mathrm{nmol} / \mathrm{L}$ vs. $9.7 \pm 1.1 \mathrm{nmol} / \mathrm{L} ; \mathrm{p}<0.001$; \pm SEM) or season of birth (summer; other; $25.5 \pm 1.6 \mathrm{nmol} / \mathrm{L}$ vs. $14.0 \pm 0.8 \mathrm{nmol} / \mathrm{L} ; \mathrm{p}<0.001$; \pm SEM). As the above mentioned stratification did not show any group differences between severe deficiency ( $\geq 1$ to $<25 \mathrm{nmol} / \mathrm{L}$ ) and moderate deficiency to sufficiency ( $\geq 25 \mathrm{nmol} / \mathrm{L}$ ) in terms of birth weight and gestational age, further analyses were performed using only two groups, either below or above the level of 250 HD detection.

Birth weight and gestational age. A highly significant difference in birth weight

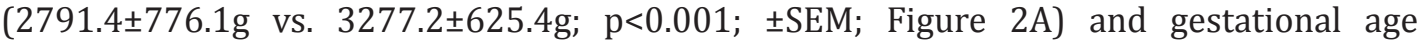

\begin{tabular}{lc}
\hline Descriptive data of the mother and the newborn (n=547) & \\
\hline Maternal age, $\mathrm{y}$ & $30.9 \pm 6.1$ \\
Maternal height, cm & $166.8 \pm 6.8$ \\
Body mass index before pregnancy, $\mathrm{kg} / \mathrm{m}^{2}$ & $22.7 \pm 4.7$ \\
Mean weight 3rd trimester of pregnancy, kg & $76.4 \pm 14.0$ \\
Hypertension before/during pregancy, \% & $3.7 / 9.5$ \\
Diabetes mellitus before/during pregnancy, \% & $1.5 / 9.4$ \\
Mean systolic BP 3rd trimester of pregnancy, mm Hg & $114.6 \pm 10.8$ \\
Mean diastolic BP 3rd trimester of pregnancy, mm Hg & $69.6 \pm 7.3$ \\
Smoking before/during pregnancy, \% & $41.2 / 15.0$ \\
Ethnicity (Caucasian/other) & $87.8 / 12.2$ \\
Income (low, medium, high) & $37.5 / 37.9 / 24.5$ \\
25OHD concentration [nmol/L] & $18.0 \pm 19.0$ \\
Primigravida/primipara, \% & $41.7 / 56.9$ \\
Gestational age at delivery, days & $271.1 \pm 16.4$ \\
Birthweight, g & $3244.3 \pm 647.5$ \\
Birthlenght, cm & $50.1 \pm 3.7$ \\
Child head circumference, cm & $34.6 \pm 1.9$ \\
Child sex, male/female, \% & $52.1 / 47.9$ \\
Apgar score at 5 min & $9.1 \pm 1.4$ \\
Apgar score at 10 min & $9.3 \pm 1.4$ \\
\hline Data are given as mean $\pm S D$ or \% & \\
\hline
\end{tabular}




\section{Kidney \\ Blood Pressure \\ Research}

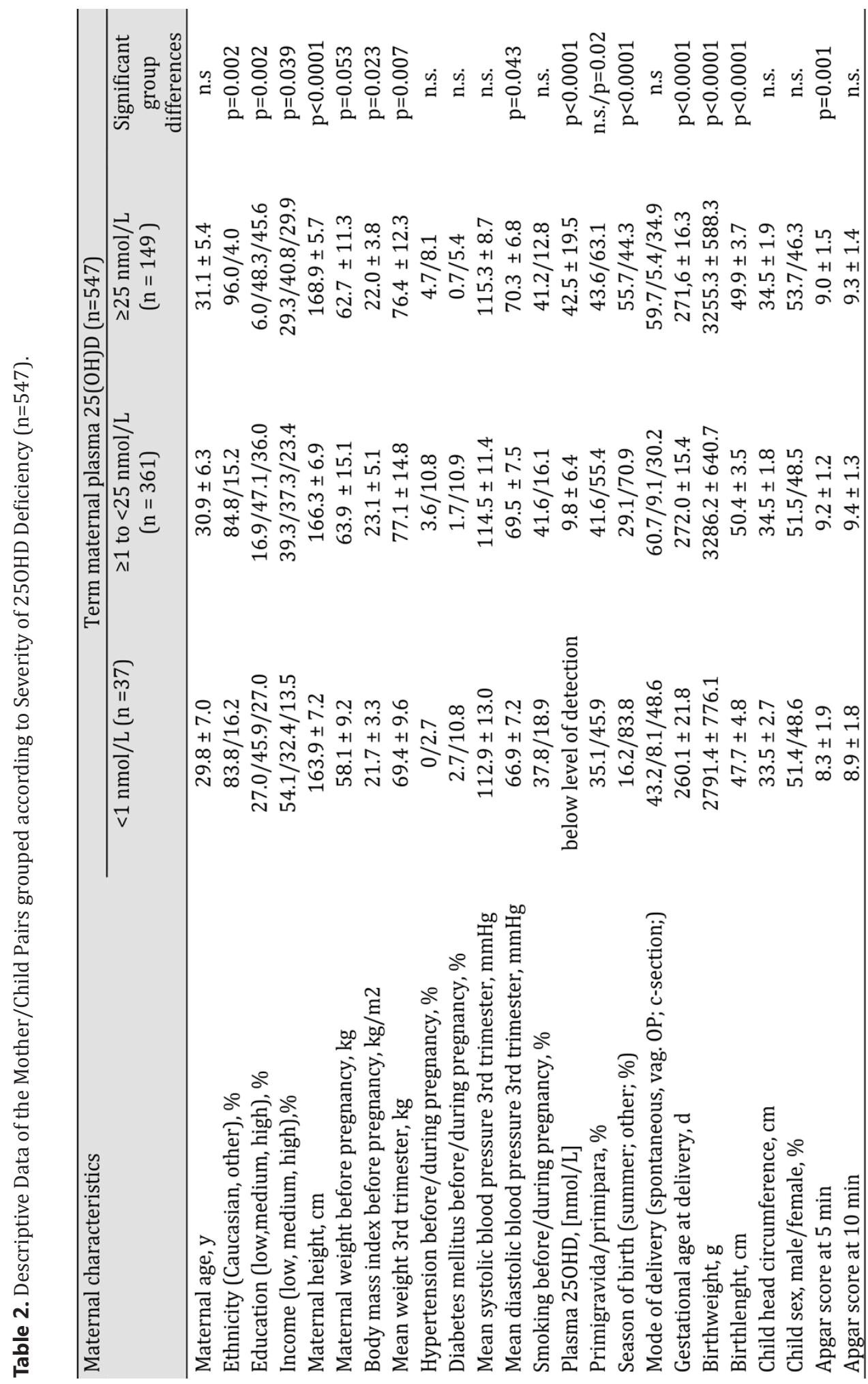

(260.1 \pm 3.6 days vs. $271.9 \pm 0.7$ days; $\mathrm{p}<0.001 ; \pm$ SEM; Figure $2 \mathrm{~B}$ ) was observed between mothers with 250HD levels below and above the threshold of detection, $1 \mathrm{nmol} / \mathrm{L}$.

Based on recent evidence from a systematic review [28] that showed associations between maternal height, birth weight and preterm birth and the strong association of 


\section{Kidney Blood Pressure Research}

Kidney Blood Press Res 2014;39:315-329

DOI: 10.1159/000355809

Published online: September 19, 2014

(C) 2014 S. Karger AG, Basel

www.karger.com/kbr Outcome
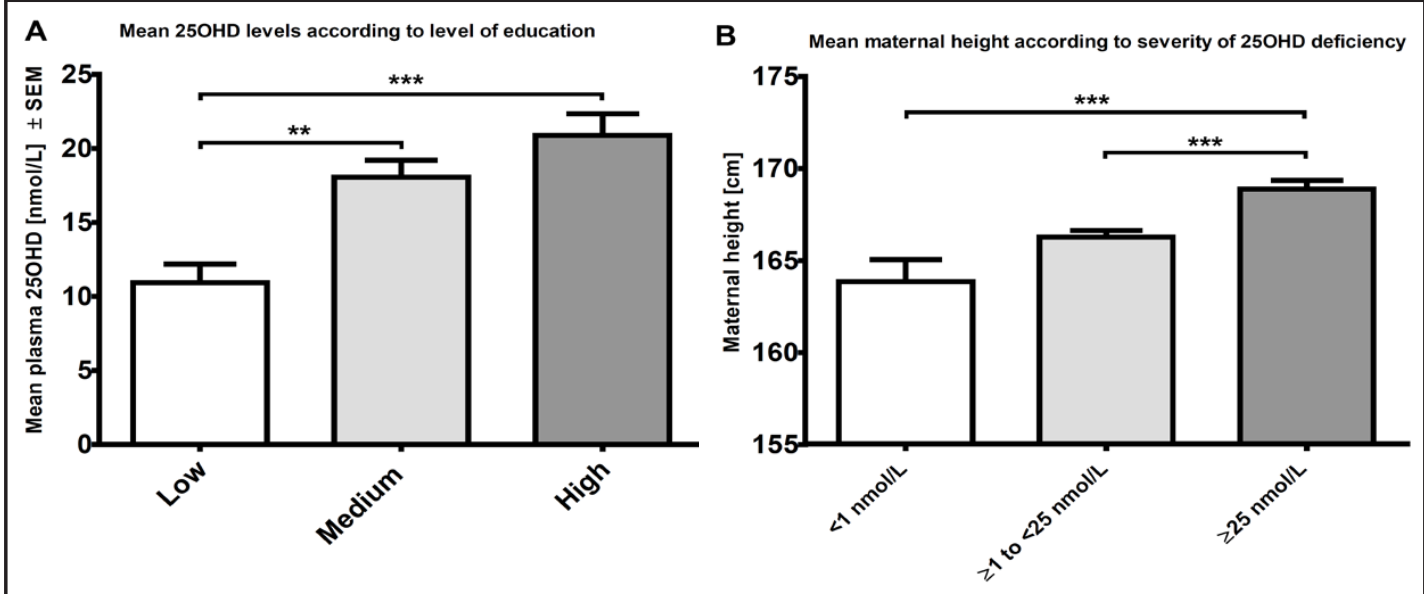

Fig. 1. Maternal 250HD plasma concentrations according to education and height. A: Maternal 250HD plasma concentration [nmol/L] according to the level of education (low education: $10.9 \pm 1.3$; medium education: 18.1 \pm 1.1 ; high education: 20.9 \pm 1.5 ; Data are given as mean $\pm \mathrm{SEM}$;); B: Maternal height according to the severity of $250 \mathrm{HD}$ deficiency $(<1 \mathrm{nmol} / \mathrm{L}: 163.9 \pm 1.2 \mathrm{~cm}$; $\geq 1$ to $<25 \mathrm{nmol} / \mathrm{L}: 166.3 \pm 0.4 \mathrm{~cm}$; $\geq 25 \mathrm{nmol} / \mathrm{L}$ : $168.9 \pm 0.5 \mathrm{~cm} ; \mathrm{p}<0.001$ Data are given as mean \pm SEM; $){ }^{* * *} \mathrm{p}<0.001 ;{ }^{* *} \mathrm{p}<0.01$.

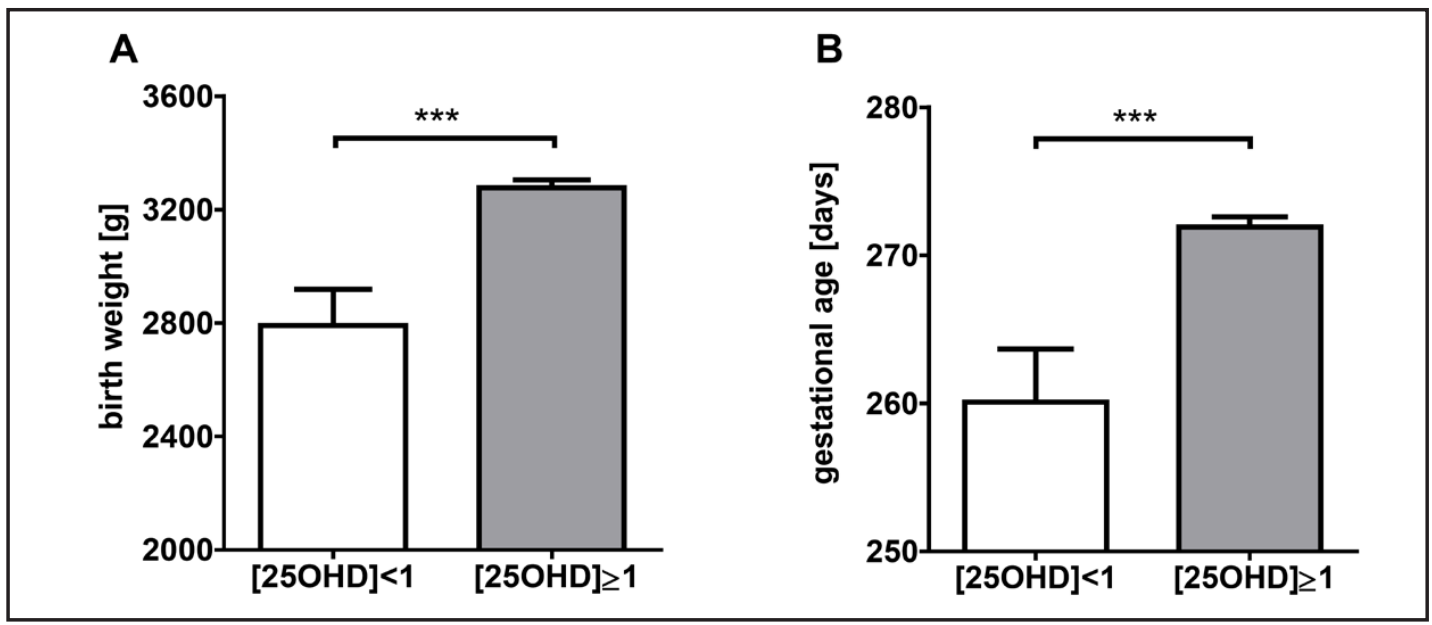

Fig. 2. Birth weight and gestational age according to chosen $250 \mathrm{HD}$ cutoff. A: Birth weight in grams ( 2791.4 \pm 776.1 g vs. $3277.2 \pm 625.4$ g; $p<0.001$; Data are given as mean \pm SEM;); B: Gestational age in days (260.1 \pm 3.6 days vs. $271.9 \pm 0.7$ days; $\mathrm{p}<0.001$; Data are given as mean $\pm \mathrm{SEM}$;) of mothers with 250 HD levels below and above the threshold of detection, $1 \mathrm{nmol} / \mathrm{L}$.

maternal height and 250HD plasma concentration in the observed cohort, maternal height and weight were used as separate confounders instead of BMI for the analysis of birth weight and gestational age.

ANCOVA analysis confirmed previous reports [27-29] that gestational age at delivery, the child's sex, maternal height, weight, and smoking during pregnancy are important variables independently associated with birth weight (Model A, Table 3). A highly significant impact of 250HD on birth weight was shown in an ANCOVA model considering grouped 250HD levels (below or above the level of detection), child sex, maternal height and weight before pregnancy, smoking during pregnancy, maternal ethnicity (Caucasian; other), education (low; medium; high;), season of birth (summer; other;) and mode of delivery (spontaneous; vaginal operation; c-section;) (Model B, Table 3). 


\section{Kidney Blood Pressure Research}

Table 3. A: ANCOVA analysis of the association between gestational age and birth weight (in g) as dependent variable; B: ANCOVA analysis of the association between maternal 250HD and birth weight (in g) as dependent variable; C: ANCOVA analysis of the association between maternal 250HD, gestational age and birth weight (in g) as dependent variable; D: ANCOVA analysis of the association between 250HD and gestational age at birth (weeks) as dependent variable; E: ANCOVA analysis of the association between 250HD and APGAR scores 5 minutes postpartum as dependent variable.

\begin{tabular}{|c|c|c|c|}
\hline Model (adjusted $\mathrm{R}^{2}$ ) and Independent Variables & $\begin{array}{c}\text { Partial Eta } \\
\text { squared }\end{array}$ & $\begin{array}{c}\text { Observed } \\
\text { power }\end{array}$ & $P$ \\
\hline \multicolumn{4}{|l|}{$A(0.590)$} \\
\hline Gestational age at delivery, $\mathrm{d}$ & 0.557 & 1.000 & $<0.0001$ \\
\hline Child sex (m/f) & 0.027 & 0.968 & $<0.0001$ \\
\hline Height before pregnancy, $\mathrm{cm}$ & 0.017 & 0.866 & 0.002 \\
\hline Weight before pregnancy, kg & 0.016 & 0.843 & 0.003 \\
\hline Smoking during pregnancy & 0.024 & 0.950 & $<0.0001$ \\
\hline Mode of delivery (spontaneous, vag. OP; c-section;) & 0.002 & 0.155 & 0.349 \\
\hline \multicolumn{4}{|l|}{$\mathrm{B}(0.100)$} \\
\hline Grouped $250 \mathrm{HD}[<1 \mathrm{vs} . \geq 1 \mathrm{nmol} / \mathrm{L}]$ & 0.020 & 0.914 & 0.0009 \\
\hline Child sex (m/f) & 0.007 & 0.517 & 0.045 \\
\hline Height before pregnancy, $\mathrm{cm}$ & 0.003 & 0.231 & 0.221 \\
\hline Weight before pregnancy, kg & 0.015 & 0.814 & 0.004 \\
\hline Smoking during pregnancy & 0.003 & 0.254 & 0.195 \\
\hline Ethnicity (caucasian; other;) & 0.003 & 0.229 & 0.224 \\
\hline Season of birth (summer; other;) & 0.002 & 0.171 & 0.315 \\
\hline Education (low; medium; high;) & 0.005 & 0.361 & 0.109 \\
\hline Mode of delivery (spontaneous, vag. OP; c-section;) & 0.045 & 0.999 & $<0.0001$ \\
\hline \multicolumn{4}{|l|}{ C (0.591) } \\
\hline Gestational age at delivery, $\mathrm{d}$ & 0.547 & 1.000 & $<0.0001$ \\
\hline Grouped $250 \mathrm{HD}[<1 \mathrm{vs} . \geq 1 \mathrm{nmol} / \mathrm{L}]$ & 0.002 & 0.160 & 0.337 \\
\hline Child sex $(\mathrm{m} / \mathrm{f})$ & 0.029 & 0.977 & $<0.0001$ \\
\hline Height before pregnancy, $\mathrm{cm}$ & 0.015 & 0.817 & 0.004 \\
\hline Weight before pregnancy, kg & 0.018 & 0.871 & 0.002 \\
\hline Smoking during pregnancy & 0.017 & 0.852 & 0.003 \\
\hline Ethnicity (caucasian; other;) & 0.004 & 0.318 & 0.137 \\
\hline Season of birth (summer; other;) & 0.002 & 0.156 & 0.345 \\
\hline Education (low; medium; high;) & 0.001 & 0.091 & 0.552 \\
\hline Mode of delivery (spontaneous, vag. OP; c-section;) & 0.002 & 0.129 & 0.414 \\
\hline \multicolumn{4}{|l|}{$\mathrm{D}(0.143)$} \\
\hline Grouped $250 \mathrm{HD}[<1 \mathrm{vs} . \geq 1 \mathrm{nmol} / \mathrm{L}]$ & 0.026 & 0.962 & $<0.0001$ \\
\hline Weight before pregnancy, $\mathrm{kg}$ & 0.015 & 0.817 & 0.004 \\
\hline Mean weight 3rd trimester, kg & 0.039 & 0.996 & $<0.0001$ \\
\hline Mean systolic blood pressure 3rd trimester, $\mathrm{mmHg}$ & 0.038 & 0.996 & $<0.0001$ \\
\hline Height before pregnancy, $\mathrm{cm}$ & 0.005 & 0.377 & 0.100 \\
\hline Smoking during pregnancy & 0.001 & 0.094 & 0.538 \\
\hline Ethnicity (caucasian; other;) & 0.000 & 0.050 & 0.978 \\
\hline Season of birth (summer; other;) & 0.000 & 0.076 & 0.634 \\
\hline Education (low; medium; high;) & 0.003 & 0.240 & 0.211 \\
\hline Mode of delivery (spontaneous, vag. OP; c-section;) & 0.059 & 1.000 & $<0.0001$ \\
\hline \multicolumn{4}{|l|}{$\mathrm{E}(0.131)$} \\
\hline Grouped $250 \mathrm{HD}[<1 \mathrm{vs} . \geq 1 \mathrm{nmol} / \mathrm{L}]$ & 0.009 & 0.609 & 0.026 \\
\hline Gestational age at delivery, $\mathrm{d}$ & 0.045 & 0.999 & $<0.0001$ \\
\hline Mode of delivery (spontaneous, vag. OP; c-section;) & 0.046 & 0.999 & $<0.0001$ \\
\hline Child sex $(\mathrm{m} / \mathrm{f})$ & 0.004 & 0.336 & 0.124 \\
\hline Ethnicity (caucasian; other;) & 0.006 & 0.438 & 0.071 \\
\hline Season of birth (summer; other;) & 0.000 & 0.077 & 0.629 \\
\hline Education (low; medium; high;) & 0.000 & 0.068 & 0.690 \\
\hline
\end{tabular}

However, additionally adding gestational age at time of birth to the model diminished a direct influence of 250HD levels on birth weight but gave rise to the question whether maternal 250HD levels impact on birth weight by influencing gestational age at birth (Model C, Table 3).

Employing bivariate correlation analysis and literature research, confounders that impact on gestational age were identified [30-32]. To investigate if maternal 250HD levels below the level of detection impact on gestational age at birth, another ANCOVA model 


\section{Kidney Blood Pressure Research}

Kidney Blood Press Res 2014;39:315-329

\begin{tabular}{l|l}
\hline DOI: 10.1159/000355809 & (c) 2014 S. Karger AG, Basel
\end{tabular}

Published onIIne: September 19, 2014

www.karger.com/kbr

was created. The model included 250HD levels (below or above the level of detection), mean systolic blood pressure in the third trimester of pregnancy, maternal height and weight before pregnancy, mean weight in the third trimester of pregnancy, smoking during pregnancy, maternal ethnicity (Caucasian; other), education (low; medium; high;), season of birth (summer; other;) and mode of delivery (spontaneous; vaginal operation; c-section;). Our data show that maternal 250HD levels below the level of detection impact on gestational age at birth strongly and statistically highly significantly (Model D, Table 3).

Furthermore another ANCOVA model using Apgar score 5 minutes postnatally as dependent variable was created. After adjusting for gestational age, mode of delivery, child sex, maternal ethnicity (Caucasian; other), education (low; medium; high;) and season of birth (summer; other;) a significant interaction between maternal 250HD levels and Apgar score 5 minutes postnatally remained (Model E, Table 3).

\section{Animal experiment}

250HD sufficient mothers gave birth to an average of $7.4 \pm 0.5$ (SEM) pups, 250HD deficient mothers to an average of $7.3 \pm 0.5$ (SEM) pups. Litter size did not differ significantly. Offspring from 250HD sufficient mothers weighed 1.29 $\pm 0.02 \mathrm{~g}$ (SEM), offspring from 25OHD insufficient mothers $1.30 \pm 0.02 \mathrm{~g}$ (SEM). There were no significant differences in birth weight. However, beginning on day 15, the offspring of 250HD deficient mothers weighed significantly less than the offspring from 250HD sufficient mothers (Figure 3A).

Figure 3B shows Kaplan Meier curves of offspring from 250HD sufficient mothers in comparison to offspring from 250HD deficient mothers. Most of the animals died before weaning from unknown causes. The rest of the animals $(n=1)$ died suddenly from unknown causes. A log-rank test between the two curves revealed a significantly higher mortality in offspring from 250HD deficient mothers $(\mathrm{p}=0.0014)$.

At an age of 55-60 days, an intraperitoneal glucose tolerance test was performed. Offspring of 250HD deficient mothers had significantly higher blood glucose levels 15 $(272.7 \pm 6.97 \mathrm{mg} / \mathrm{dl}$ vs. $307.4 \pm 8.31 \mathrm{mg} / \mathrm{dl}, \mathrm{p}<0.01), 30(261.0 \pm 8.54 \mathrm{mg} / \mathrm{dl}$ vs. $289.4 \pm 7.69 \mathrm{mg} /$ $\mathrm{dl}, \mathrm{p}<0.05)$ and 45 minutes $(209.0 \pm 8.93 \mathrm{mg} / \mathrm{dl}$ vs. $235.1 \pm 7.09 \mathrm{mg} / \mathrm{dl}, \mathrm{p}<0.05)$ after the intraperitoneal glucose load (Figure 3C; Data are given \pm SEM;). Blood pressure was also assessed in offspring from 250HD sufficient and insufficient mothers. Offspring of 250HD sufficient mothers showed a mean systolic blood pressure of $94.4 \pm 2.3$ (SEM) $\mathrm{mmHg}$ and offspring from 250HD deficient mothers a mean systolic blood pressure of $92.5 \pm 2.1$ (SEM) mmHg. There was no statistically significant difference in measured systolic blood pressure. To see whether or not the respective diets resulted in maternal 250HD sufficiency and insufficiency, 250HD was measured in 3 animals of each diet group. 250HD deficient mice displayed serum 250HD concentrations of 4.83 \pm 0.94 (SEM), whereas 250HD sufficient animals had serum concentrations of $83.58 \pm 6.39$ (SEM) nmol/L.

\section{Discussion}

The present study demonstrated in a large, apparently healthy pregnancy cohort that there is a relationship between the maternal 250HD status and birth weight of the newborn, i.e., low maternal 250HD levels are associated with low birth weight. A more detailed analysis revealed that low $250 \mathrm{HD}$ levels are linked to low birth weight by controlling gestational age. Additionally it was shown that low maternal 250HD levels also impact on the APGAR score of the newborn. To demonstrate that low maternal 250HD status causes phenotypic effects in the offspring, an animal study was performed. Offspring of 250HD sufficient mice was compared to offspring of 250HD insufficient mice. Offspring of 250HD insufficient mice showed a significantly stunted postnatal growth and a higher mortality than offspring of 250HD sufficient mothers. A glucose tolerance test performed at the end of the experiment showed that offspring born to 250HD insufficient mice display an impaired glucose tolerance. Since birth weight and prematurity are associated with an adverse renal and cardio- 


\section{Kidney \\ Blood Pressure Research}

Fig. 3. Growth curves, survival and glucose tolerance of 250HD sufficient and insufficient mice. A: Growth curves of offspring from 250HD sufficient (white squares) and insufficient (grey circles) mothers. ${ }^{* * *} \mathrm{p}<0.001 ;{ }^{* *} \mathrm{p}<0.01 ;{ }^{*} \mathrm{p}<0.05$; n.s.: not significant; B: Kaplan Meier curves of offspring from 250HD sufficient mothers in comparison to offspring from 250HD deficient mothers. There was a significantly higher mortality in offspring from 250HD deficient mothers (log-rank test; $\mathrm{p}=0.0014$ ); C: Results from the intraperitoneal glucose tolerance test comparing offspring from 250HD sufficient to offspring from 250HD insufficient mothers. Offspring of 250HD deficient mothers had significantly higher blood glucose levels $15(272.7 \pm 6.97 \mathrm{mg} / \mathrm{dl}$ vs. $307.4 \pm 8.31 \mathrm{mg} / \mathrm{dl}), 30(261.0 \pm 8.54 \mathrm{mg} /$ dl vs. $289.4 \pm 7.69 \mathrm{mg} / \mathrm{dl}$ ) and 45 minutes $(209.0 \pm 8.93 \mathrm{mg} / \mathrm{dl}$ vs. $235.1 \pm 7.09 \mathrm{mg} /$ dl) after the intraperitoneal glucose load. Data are given as mean $\pm \mathrm{SEM}$; ${ }^{* *} \mathrm{p}<0.01$; $* \mathrm{p}<0.05$.

vascular outcome in later life, this study emphasizes the need for novel monitoring and treatment guidelines of 250HD during pregnancy to improve cardiovascular outcome in later life.

The finding that very low maternal 250HD plasma concentrations levels are associated with low birth weight, is in line with current literature [22, 23]. However, ambiguous data on the influence of 250HD on birth weight are published as some studies did not detect an impact of low 250HD on birth weight [21] .

Recent systematic reviews point out that the association between low maternal 250HD concentrations and birth weight is genuine [33,34]. Our study adds a different, not yet performed approach for the assessment of the impact of 250HD on birth outcomes. Patients were stratified into groups depending on their 250HD plasma concentration $(<1 \mathrm{nmol} / \mathrm{L}$; $\geq 1$ to $<25 \mathrm{nmol} / \mathrm{L} ; \geq 25 \mathrm{nmol} / \mathrm{L}$ ) differently from other studies, because of the very high frequency of $250 \mathrm{HD}$ deficiency in the analyzed cohort. Most other studies used different stratification, regarding higher gestational levels of 250HD already as insufficiency [33]. In meta-analyses it was shown that the chosen cut-off value is important to detect effects of

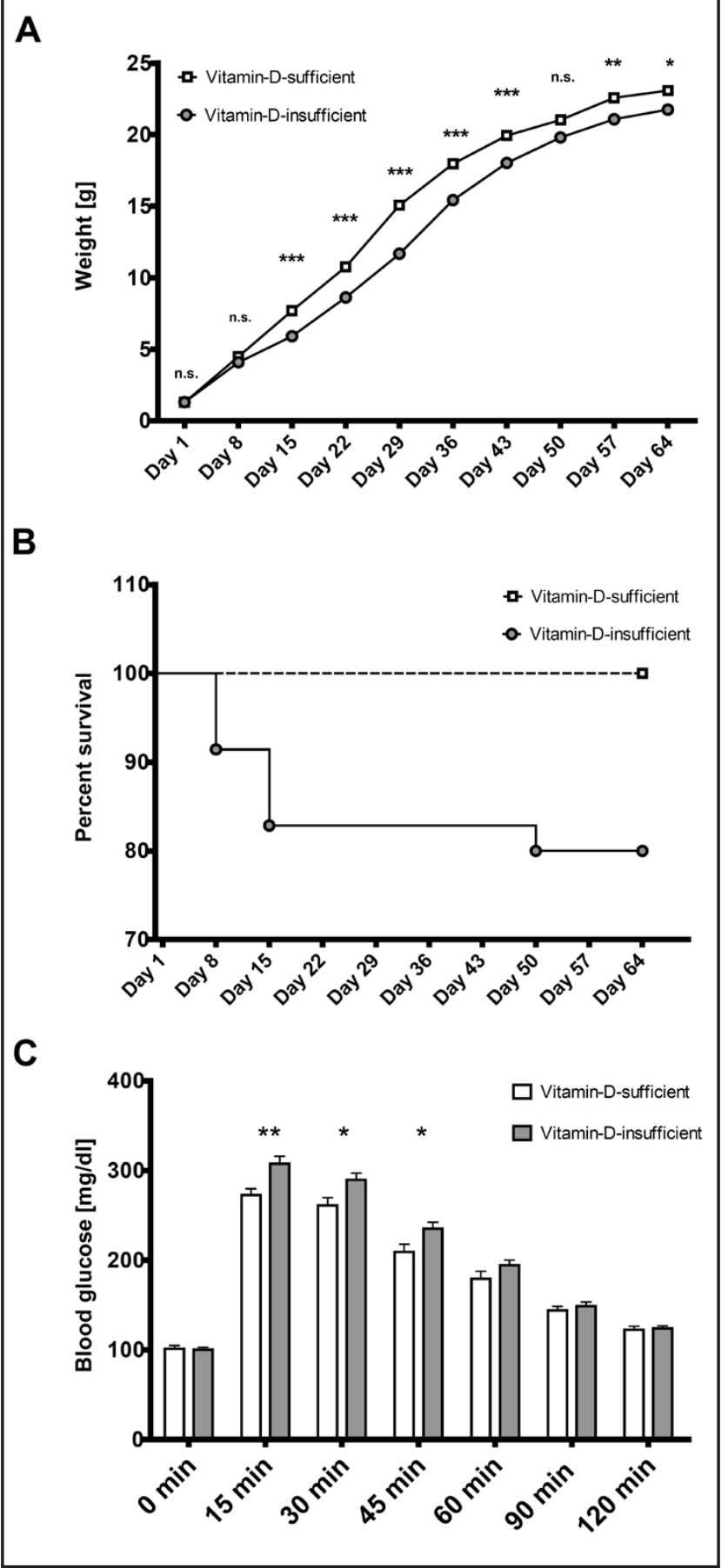




\section{Kidney Blood Pressure Research}

Kidney Blood Press Res 2014;39:315-329

\begin{tabular}{l|l}
\hline DOI: 10.1159/000355809 & (c) 2014 S. Karger AG, Basel
\end{tabular}

Published onIIne: September 19, 2014

www.karger.com/kbr

Reichetzeder/Chen/Föller/Slowinski/Li/Chen/Lang/Hocher: Vitamin D and Pregnancy Outcome

250HD on anthropometric measurements [33]. The time point of blood sampling might be one explanation why such a high frequency of $250 \mathrm{HD}$ deficiency was observed. It is well known that 250HD deficiency is a major common public health problem [9, 10, 35]. It was also shown that 250HD levels decline at the end of pregnancy [12]. Given these two factors, it is possible that the time point of blood sampling at term is in part responsible for the observed very low 250HD levels. Although the frequency of patients with 250HD levels considered low was exceptionally high, this present study was able to distinguish a group of extremely deficient mothers that were at high risk for impaired birth outcomes.

Results of this clinical study suggest that extremely low maternal 250HD concentrations impact on birth weight by shortening the duration of gestation. This observation is in line with literature. Very recent studies were able to show similar results. In a multicenter U.S. study by Bodnar et al., it was observed that gestational serum 250HD concentrations above $30 \mathrm{nmol} / \mathrm{L}$ are associated with a $20 \%-30 \%$ reduction in the risk of spontaneous preterm birth compared with 250HD concentrations less than $30 \mathrm{nmol} / \mathrm{L}$ [36]. Different from the present study, blood samples were taken at 26 weeks gestation or earlier and the observation was only made in non-Caucasian mothers. The authors mentioned though, that it is possible that there were not enough cases of white women with $250 \mathrm{HD}$ levels less than $30 \mathrm{nmol} / \mathrm{L}$ in their cohort to detect an effect [36]. A limitation of the just mentioned study is that blood samples were already collected around 50 years ago between 1959 and 1965 and might have shown signs of analyte deterioration [36, 37]. Another study assessing the 250HD status of prematurely and term born newborns was able to demonstrate that newborns born before 32 weeks of gestation were at higher risk of having insufficient 250HD levels [38]. The results of our study, together with previous reports [36, 38, 39] underline an involvement of 250HD in controlling gestational age. Biologically, it would be plausible that low gestational maternal 250HD levels are involved in triggering shortening of gestation. It is known that low gestational 250HD concentrations are associated with bacterial vaginosis [16] and infection is one risk factor of preterm labour [40]. Vitamin D is also involved in gene regulation important for trophoblast invasion and angiogenesis [41], other important factors involved in preterm labour [42]. In the above mentioned study by Bodnar et al. it was shown in histologic examinations of the placenta, that low maternal 250HD concentrations are associated with both inflammatory and vascular placental lesions [36]. Another study investigated the effect of 250HD deficiency on birth weight in relation to placental weight, a known factor impacting on birth weight. It was shown that 250HD deficiency is associated with low birth weight, but independently of placental weight [43].

We observed differences in maternal height, according to the severity of 250HD deficiency in this study. The more deficient mothers were for 250HD, the smaller they were. To the best of our knowledge, this observation was only made by two other groups before $[44,45]$. Given the involvement of $250 \mathrm{HD}$ in bone metabolism it was suggested that long term 250HD deficiency might impact on longitudinal bone growth [44]. It was also hypothesized that bone mineral content and density during times of 250HD deficiency are maintained in normal ranges at the expense of body height [45]. In context with data from a recent meta analysis, that showed an association between maternal short stature and preterm birth, these associations warrant further attention by future studies [28].

To assess whether or not the impact of low maternal 250HD levels is not just associative but causative, an animal experiment mimicking the clinical situation was performed. Mice were put on diets insufficient or sufficient for vitamin $\mathrm{D}_{3}$ and mated with male mice on standard diets. Maternal 250HD insufficiency was confirmed by measuring plasma levels. The F1 generation was explicitly characterized to detect possible effects of developmental programming, which can be linked to low birth weight [1] or prematurity [2, 46-48]. Results from the animal experiment indicated a direct involvement of maternal 250HD in gestation, birth outcomes and fetal programming of adult disease in later life. No statistical significant differences were observed regarding birth weight. This is in line with our clinical data, since only women with extremely low 250HD concentrations $(<1 \mathrm{nmol} / \mathrm{L})$ had offspring with substantially reduced birth weight. If the maternal $250 \mathrm{HD}$ concentration was in the range 


\section{Kidney Blood Pressure Research}

Kidney Blood Press Res 2014;39:315-329

\begin{tabular}{l|l}
\hline DOI: 10.1159/000355809 & (c) 2014 S. Karger AG, Basel
\end{tabular}

Published onlıne: september 19, 2014

www.karger.com/kbr

Reichetzeder/Chen/Föller/Slowinski/Li/Chen/Lang/Hocher: Vitamin D and Pregnancy Outcome

of that seen in the animal study in the 250HD deficient group, the effect on birth weight in the human study was minor. Other groups investigating the effects of gestational 250HD deficiency in rodent models on the offspring did not see differences in birth weight either [5]. One study even demonstrated that offspring from 250HD deficient mice is significantly larger at day E14 and E18 than offspring from sufficient mothers. This weight difference was not present at time of birth and reversed after birth, with offspring from 250HD deficient mice being significantly lighter from postnatal day 14 on [49], an effect that was also observed in the present study.

Beyond birth weight, the offspring of 250HD deficient mothers presented a strongly altered phenotype with a significantly reduced postnatal growth rate until the end of the study and an increased mortality. The observed higher mortality in offspring of 250HD deficient mothers supports the concept of low gestational 250HD levels triggering a shortening of gestation as prematurity is strongly associated with an elevated mortality [50, 51]. The observation that low gestational $250 \mathrm{HD}$ also causes prematurity in rodent models is supported by a study from Liu et al. which focused on prenatal morphology of offspring from 250HD deficient mice. They showed that maternal gestational 250HD deficiency leads to a higher rate of premature births, that is even comparable to established knockout models of prematurity $[49,52]$.

A hallmark of fetal programming is the development of symptoms of metabolic syndrome in later life, i.e. development of hypertension and changes in glucose and lipid metabolism [1]. To detect symptoms of metabolic syndrome in this study, blood pressure and glucose tolerance were assessed in offspring from 250HD sufficient and insufficient dams. No statistical significant differences were seen in systolic blood pressure, maybe because the time point of measurement, at postnatal day 55, was too early. In a study in rats investigating the consequences of low gestational vitamin D on kidney development it was shown that offspring of mothers receiving diets insufficient for Vitamin $\mathrm{D}_{3}$ started to develop significantly higher systolic blood pressure than offspring from mothers on sufficient diets at an age of 3 months [5]. The glucose tolerance test, which was also performed at an age of 55-60 days showed that offspring from 250HD deficient mothers had an impaired glucose tolerance. This is quite remarkable as these mice were to be seen as pre-adult animals at the time of the test. This result fits to newer concepts of fetal programming generated by large epidemiological studies. These indicated that regardless of the setting, the most prominent feature of fetal programming is a modification of insulin signaling and that low birth weight is already at time of birth associated with elevated surrogate parameters of insulin resistance $[53,54]$. It has been shown that 250HD deficiency is associated with impaired insulin secretion, reduced glucose homeostasis, increased risk of metabolic syndrome and type 2 diabetes $[55,56]$.

However, evidence remains inconclusive, as data from randomized controlled trials on 250HD supplementation failed to show positive effects of 250HD supplementation on the incidence of diabetes, glucose control and insulin resistance in general populations [57]. Our data in mice demonstrate for the first time that vitamin D programs glycemic control -a key element of the metabolic syndrome. However, the underlying mechanism (impaired insulin secretion or increased insulin resistance) needs to be addressed in clamp studies.

Our study investigated the effects of low gestational 250HD levels on birth outcomes in a clinical and an experimental setting. Results from both approaches indicated an important role of low gestational 250HD on birth weight, preterm delivery and postnatal life. Additionally, data from the animal experiment demonstrated that low gestational 250HD levels also elicit effects on developmental programming and cause an impairment of glucose tolerance in later life.

The molecular pathways causing fetal programming are linked to epigenetic modifications. With respect to vitamin $\mathrm{D}$, it is known that vitamin $\mathrm{D}$ interacts with the epigenome on several different levels. Important genes involved in vitamin D signaling and metabolism, such as the vitamin D receptor and the enzymes 25 -hydroxylase, $1 \alpha$-hydroxylase and 24-hydroxylase possess large $\mathrm{CpG}$ islands in their promoter regions and can be regulated 


\section{Kidney \\ Blood Pressure Research}

Kidney Blood Press Res 2014;39:315-329

\begin{tabular}{l|l}
\hline DOI: $10.1159 / 000355809$ & C 2014 S. Karger AG, Basel
\end{tabular}

Published onIIne: September 19, 2014

www.karger.com/kbr

Outcome

by DNA methylation [58]. Beyond that, multiple genes encoding for chromatin modifiers and remodelers, such as histone demethylases of the Jumonji C-domain-containing-proteins and lysine-specific demethylase families are primary targets of the vitamin D receptor and its ligands [58]. There is also evidence that certain VDR ligands evoke DNA demethylating effects [58].

The impact of low 250HD levels on birth outcomes such as preterm delivery and birth weight is of medical and socioeconomic relevance given the large body of evidence that both, low birth weight and prematurity can alter disease risk in adult life [1, 2, 46-48]. Vitamin D deficiency during pregnancy leads to an exposure of the growing fetus to inadequate levels of vitamin $\mathrm{D}$, which is an essential factor for a normal development. It is now well-established that the antecedents of cardiovascular disease can originate very early in life. Endocrine factors like maternal vitamin D deficiency as seen in the current study but also alterations of the fetal and maternal renin-angiotensin system have the potential to program long-term vulnerability to hypertension, metabolic- and cardiovascular disease $[59,60]$.

\section{Conclusion}

This study demonstrates that maternal 250HD in human pregnancy is associated with offspring birth weight. The effect of $250 \mathrm{HD}$ on birth weight is most likely mediated by vitamin D controlling gestational age. Results from an animal experiment suggest that gestational 250HD insufficiency is causally linked to increased perinatal mortality and impaired glucose tolerance.

It is well established that both low birth weight and also prematurity are associated with an adverse renal and cardiovascular outcome in later life. Since 250HD deficiency is a treatable condition, the current study emphasizes the need for novel monitoring and treatment guidelines of $250 \mathrm{HD}$ during pregnancy to improve cardiovascular outcome in later life.

\section{Disclosure Statement}

The authors of this manuscript state that they do not have any conflict of interests and nothing to disclose.

\section{Acknowledgments}

We would like to thank all the participating mothers without whom this study would not have been possible. This study was partially funded by Deutsche Forschungsgemeinschaft (DFG). Hong Chen was supported by the state of BadenWürttemberg (Landesgraduiertenförderung).

\section{References}

1 Rinaudo P, Wang E: Fetal programming and metabolic syndrome. Annu Rev Physiol 2012;74:107-130.

-2 De Jong F, Monuteaux MC, van Elburg RM, Gillman MW, Belfort MB: Systematic review and meta-analysis of preterm birth and later systolic blood pressure. Hypertension 2012;59:226-234.

3 Morris HA, Anderson PH: Autocrine and paracrine actions of vitamin D. Clin Biochem Rev 2010;31:129138.

-4 Lee SS, Schroeder FC: Steroids as Central Regulators of Organismal Development and Lifespan. PLoS Biol 2012;10:e1001307. 


\section{Kidney \\ Blood Pressure Research}

Kidney Blood Press Res 2014;39:315-329

\begin{tabular}{l|l}
\hline DOI: $10.1159 / 000355809$ & C 2014 S. Karger AG, Basel
\end{tabular}

Published onIIne: September 19, 2014

www.karger.com/kbr

Reichetzeder/Chen/Föller/Slowinski/Li/Chen/Lang/Hocher: Vitamin D and Pregnancy Outcome

5 Nascimento FAM, Ceciliano TC, Aguila MB, Mandarim-de-Lacerda CA: Maternal vitamin D deficiency delays glomerular maturity in F1 and F2 offspring. PLoS ONE 2012;7:e41740.

6 McGrath J: Does "imprinting” with low prenatal vitamin D contribute to the risk of various adult disorders? Med Hypotheses 2001;56:367-371.

7 Halhali A, Acker GM, Garabédian M: 1,25-Dihydroxyvitamin D3 induces in vivo the decidualization of rat endometrial cells. J Reprod Fertil 1991;91:59-64.

-8 Shin JS, Choi MY, Longtine MS, Nelson DM: Vitamin D Effects on Pregnancy and the Placenta. Placenta 2010;31:1027-1034.

-9 Vandevijvere S, Amsalkhir S, Van Oyen H, Moreno-Reyes R: High prevalence of vitamin D deficiency in pregnant women: a national cross-sectional survey. PLoS ONE 2012;7:e43868.

-10 Dawodu A, Wagner CL: Mother-child vitamin D deficiency: an international perspective. Arch Dis Child 2007;92:737-740.

-11 Ardawi MS, Nasrat HA, Ba'Aqueel HS: Calcium-regulating hormones and parathyroid hormone-related peptide in normal human pregnancy and postpartum: a longitudinal study. Eur J Endocrinol 1997;137:402409.

12 Fernández-Alonso AM, Dionis-Sánchez EC, Chedraui P, González-Salmerón MD, Pérez-López FR, Spanish Vitamin D and Women's Health Research Group: First-trimester maternal serum 25-hydroxyvitamin $\mathrm{D}_{3}$ status and pregnancy outcome. Int J Gynaecol Obstet 2012;116:6-9.

13 Bodnar LM, Catov JM, Simhan HN, Holick MF, Powers RW, Roberts JM: Maternal vitamin D deficiency increases the risk of preeclampsia. J Clin Endocrinol Metab 2007;92:3517-3522.

-14 Burris HH, Rifas-Shiman SL, Kleinman K, Litonjua AA, Huh SY, Rich-Edwards JW, Camargo Jr CA, Gillman MW: Vitamin D deficiency in pregnancy and gestational diabetes mellitus. Am J Obstet Gynecol 2012;207:182.e1-182.e8.

15 Merewood A, Mehta SD, Chen TC, Bauchner H, Holick MF: Association between Vitamin D Deficiency and Primary Cesarean Section. J Clin Endocrinol Metab 2009;94:940-945.

-16 Bodnar LM, Krohn MA, Simhan HN: Maternal Vitamin D Deficiency Is Associated with Bacterial Vaginosis in the First Trimester of Pregnancy. J Nutr 2009;139:1157-1161.

17 Parr JH, Ramsay I: The presentation of osteomalacia in pregnancy. Case report. Br J Obstet Gynaecol 1984;91:816-818.

18 Robinson PD, Högler W, Craig ME, Verge CF, Walker JL, Piper AC, Woodhead HJ, Cowell CT, Ambler GR: The re-emerging burden of rickets: a decade of experience from Sydney. Arch Dis Child 2006;91:564-568.

19 Morley R, Carlin JB, Pasco JA, Wark JD: Maternal 25-hydroxyvitamin D and parathyroid hormone concentrations and offspring birth size. J Clin Endocrinol Metab 2006;91:906-912.

20 Gale CR, Robinson SM, Harvey NC, Javaid MK, Jiang B, Martyn CN, Godfrey KM, Cooper C: Maternal vitamin D status during pregnancy and child outcomes. Eur J Clin Nutr 2008;62:68-77.

21 Farrant HJ, Krishnaveni GV, Hill JC, Boucher BJ, Fisher DJ, Noonan K, Osmond C, Veena SR, Fall CH: Vitamin $\mathrm{D}$ insufficiency is common in Indian mothers but is not associated with gestational diabetes or variation in newborn size. Eur J Clin Nutr 2009;63:646-652.

-22 Bodnar LM, Catov JM, Zmuda JM, Cooper ME, Parrott MS, Roberts JM, Marazita ML, Simhan HN: Maternal serum 25-hydroxyvitamin D concentrations are associated with small-for-gestational age births in white women. J Nutr 2010;140:999-1006.

23 Burris HH, Rifas-Shiman SL, Camargo CA Jr, Litonjua AA, Huh SY, Rich-Edwards JW, Gillman MW: Plasma 25-hydroxyvitamin D during pregnancy and small-for-gestational age in black and white infants. Ann Epidemiol 2012;22:581-586.

24 Urrutia RP, Thorp JM: Vitamin D in Pregnancy: Current Concepts. Curr Opin Obstet Gynecol 2012;24:57-64.

25 Holick MF, Binkley NC, Bischoff-Ferrari HA, Gordon CM, Hanley DA, Heaney RP, Murad MH, Weaver CM, Endocrine Society: Evaluation, treatment, and prevention of vitamin D deficiency: an Endocrine Society clinical practice guideline. J Clin Endocrinol Metab 2011;96:1911-1930.

26 Hornung RW, Reed LD: Estimation of Average Concentration in the Presence of Nondetectable Values. Appl Occup Environ Hyg 1990;5:46-51.

27 Abell TD, Baker LC, Ramsey CN Jr: The effects of maternal smoking on infant birth weight. Fam Med 1991;23:103-107. 


\section{Kidney \\ Blood Pressure Research}

Kidney Blood Press Res 2014;39:315-329

\begin{tabular}{l|l}
\hline DOI: 10.1159/000355809 & C 2014 S. Karger AG, Basel
\end{tabular}

Published onIIne: September 19, 2014

www.karger.com/kbr

28 Han Z, Lutsiv 0, Mulla S, McDonald SD: Maternal height and the risk of preterm birth and low birth weight: a systematic review and meta-analyses. J Obstet Gynaecol Can 2012;34:721-746.

29 Camilleri AP: The obstetric significance of short stature. Eur J Obstet Gynecol Reprod Biol 1981;12:347356.

-30 Cnattingius S, Bergström R, Lipworth L, Kramer MS: Prepregnancy weight and the risk of adverse pregnancy outcomes. N Engl J Med 1998;338:147-152.

-31 Gwin KM, Schrader R, Peters K, Moreno A, Thiel KW, Leslie KK: An exploratory study of the variables impacting preterm birth rates in New Mexico. BMC Pregnancy Childbirth 2012;12:53.

-32 Cnattingius S, Villamor E, Johansson S, Edstedt Bonamy AK, Persson M, Wikström AK, Granath F: Maternal obesity and risk of preterm delivery. JAMA 2013;309:2362-2370.

33 Wei S-Q, Qi H-P, Luo Z-C, Fraser WD: Maternal vitamin D status and adverse pregnancy outcomes: a systematic review and meta-analysis. J Matern Fetal Neonatal Med 2013;26:889-899.

34 Aghajafari F, Nagulesapillai T, Ronksley PE, Tough SC, O’Beirne M, Rabi DM: Association between maternal serum 25-hydroxyvitamin D level and pregnancy and neonatal outcomes: systematic review and metaanalysis of observational studies. BMJ 2013;346:f1169.

35 Markestad T, Elzouki A, Legnain M, Ulstein M, Aksnes L: Serum concentrations of vitamin D metabolites in maternal and umbilical cord blood of Libyan and Norwegian women. Hum Nutr Clin Nutr 1984;38:55-62.

-36 Bodnar LM, Klebanoff MA, Gernand AD, Platt RW, Parks WT, Catov JM, Simhan HN: Maternal vitamin D status and spontaneous preterm birth by placental histology in the US Collaborative Perinatal Project. Am J Epidemiol 2014;179:168-176.

-37 Bodnar LM, Catov JM, Wisner KL, Klebanoff MA: Racial and seasonal differences in 25-hydroxyvitamin D detected in maternal sera frozen for over 40 years. Br J Nutr 2009;101:278-284.

-38 Burris HH, Van Marter LJ, McElrath TF, Tabatabai P, Litonjua AA, Weiss ST, Christou H: Vitamin D status among preterm and full-term infants at birth. Pediatr Res 2014;75:75-80.

-39 Bodnar LM, Rouse DJ, Momirova V, Peaceman AM, Sciscione A, Spong CY, Varner MW, Malone FD, Iams JD, Mercer BM, Thorp JM Jr, Sorokin Y, Carpenter MW, Lo J, Ramin SM, Harper M: Maternal 25-hydroxyvitamin $\mathrm{d}$ and preterm birth in twin gestations. Obstet Gynecol 2013;122:91-98.

40 Mendz GL, Kaakoush NO, Quinlivan JA: Bacterial aetiological agents of intra-amniotic infections and preterm birth in pregnant women. Front Cell Infect Microbiol 2013;3:58.

41 Evans KN, Bulmer JN, Kilby MD, Hewison M: Vitamin D and placental-decidual function. J Soc Gynecol Investig 2004;11:263-271.

-42 Stanek J: Comparison of placental pathology in preterm, late-preterm, near-term, and term births. Am J Obstet Gynecol 2014;210:234.e1-6.

43 Gernand AD, Simhan HN, Klebanoff MA, Bodnar LM: Maternal serum 25-hydroxyvitamin D and measures of newborn and placental weight in a U.S. multicenter cohort study. J Clin Endocrinol Metab 2013;98:398404.

44 Kremer R, Campbell PP, Reinhardt T, Gilsanz V: Vitamin D Status and Its Relationship to Body Fat, Final Height, and Peak Bone Mass in Young Women. J Clin Endocrinol Metab 2009;94:67-73.

45 Hatun S, Islam 0, Cizmecioglu F, Kara B, Babaoglu K, Berk F, Gökalp AS: Subclinical vitamin D deficiency is increased in adolescent girls who wear concealing clothing. J Nutr 2005;135:218-222.

-46 Irving RJ, Belton NR, Elton RA, Walker BR: Adult cardiovascular risk factors in premature babies. Lancet 2000;355:2135-2136.

47 Hofman PL, Regan F, Jackson WE, Jefferies C, Knight DB, Robinson EM, Cutfield WS: Premature birth and later insulin resistance. N Engl J Med 2004;351:2179-2186.

48 Parkinson JRC, Hyde MJ, Gale C, Santhakumaran S, Modi N: Preterm birth and the metabolic syndrome in adult life: a systematic review and meta-analysis. Pediatrics 2013;131:e1240-1263.

49 Liu NQ, Ouyang Y, Bulut Y, Lagishetty V, Chan SY, Hollis BW, Wagner C, Equils O, Hewison M: Dietary vitamin $D$ restriction in pregnant female mice is associated with maternal hypertension and altered placental and fetal development. Endocrinology 2013;154:2270-2280.

50 Adams Waldorf KM, Rubens CE, Gravett MG: Use of nonhuman primate models to investigate mechanisms of infection-associated preterm birth. BJOG 2011;118:136-144.

-51 Galinsky R, Polglase GR, Hooper SB, Black MJ, Moss TJM: The consequences of chorioamnionitis: preterm birth and effects on development. J Pregnancy 2013;2013:412831. 


\section{Kidney \\ Blood Pressure Research}

\section{Kidney Blood Press Res 2014;39:315-329}

DOI: 10.1159/000355809

Published onlıne: september 19, 2014

(C) 2014 S. Karger AG, Basel

www.karger.com/kbr

Reichetzeder/Chen/Föller/Slowinski/Li/Chen/Lang/Hocher: Vitamin D and Pregnancy Outcome

-52 Calmus ML, Macksoud EE, Tucker R, Iozzo RV, Lechner BE: A mouse model of spontaneous preterm birth based on the genetic ablation of biglycan and decorin. Reproduction 2011;142:183-194.

-53 Pfab T, Slowinski T, Godes M, Halle H, Priem F, Hocher B: Low birth weight, a risk factor for cardiovascular diseases in later life, is already associated with elevated fetal glycosylated hemoglobin at birth. Circulation 2006;114:1687-1692.

54 Li J, Wang Z-N, Schlemm L, Pfab T, Xiao X-M, Chen Y-P, Hocher B: Low birth weight and elevated head-toabdominal circumference ratio are associated with elevated fetal glycated serum protein concentrations. J Hypertens 2011;29:1712-1718.

-55 Forouhi NG, Luan J, Cooper A, Boucher BJ, Wareham NJ: Baseline serum 25-hydroxy vitamin d is predictive of future glycemic status and insulin resistance: the Medical Research Council Ely Prospective Study 19902000. Diabetes 2008;57:2619-2625.

56. Boucher BJ, Mannan N, Noonan K, Hales CN, Evans SJ: Glucose intolerance and impairment of insulin secretion in relation to vitamin D deficiency in east London Asians. Diabetologia 1995;38:1239-1245.

57 Pilz S, Kienreich K, Rutters F, de Jongh R, van Ballegooijen AJ, Grübler M, Tomaschitz A, Dekker JM: Role of vitamin D in the development of insulin resistance and type 2 diabetes. Curr Diab Rep 2013;13:261-270.

58 Fetahu IS, Höbaus J, Kállay E: Vitamin D and the epigenome. Front Physiol 2014;5:164.

59 Gezmish 0, Black MJ: Vitamin D deficiency in early life and the potential programming of cardiovascular disease in adulthood. J Cardiovasc Transl Res 2013;6:588-603.

60 Chen Y-P, Lu Y-P, Li J, Liu Z-W, Chen W-J, Liang X-J, Chen X, Wen W-R, Xiao X-M, Reichetzeder C, Hocher B: Fetal and maternal angiotensin (1-7) are associated with preterm birth. J Hypertens 2014;32:1833-1841. 